\title{
Characteristics of urban gardens and their accessibility to locals and non-locals in Taipei City, Taiwan
}

\section{Hongwei Hsiao}

\begin{tabular}{|c|l|}
\hline Citation & Landscape and Ecological Engineering. 17(1); 41-53 \\
\hline Issue Date & $2021-01$ \\
\hline Type & Journal Article \\
\hline Textversion & Author \\
\hline Rights & $\begin{array}{l}\text { This version of the article has been accepted for publication, after peer review } \\
\text { (when applicable) and is subject to Springer Nature's AM terms of use, but is not } \\
\text { the Version of Record and does not reflect post-acceptance improvements, or any } \\
\text { corrections. The Version of Record is available online at: } \\
\text { https://doi.org/10.1007/s11355-020-00430-x. } \\
\text { See Springer Nature terms of reuse. } \\
\text { https://www.springer.com/gp/open-access/publication-policies/aam-terms-of-use }\end{array}$ \\
\hline DOI & \begin{tabular}{l}
$10.1007 /$ s11355-020-00430-x \\
\hline
\end{tabular}
\end{tabular}

Self-Archiving by Author(s)

Placed on: Osaka City University Repository

Hsiao, H. Characteristics of urban gardens and their accessibility to locals and non-locals in Taipei City, Taiwan. Landscape and Ecological Engineering. 17, 41-53 (2021). 
Characteristics of urban gardens and their accessibility to locals and non-locals in Taipei City, Taiwan

\title{
Hongwei HSIAO*1
}

${ }^{* 1}$ Associate Professor, Graduate School of Engineering, Osaka City University. Ph.D. [Email address] sho@gm.osaka-cu.ac.jp

[Postal address] 558-8585 Room C423, Faculty of Eng. Osaka City Univ. 3-3-138, Sugimoto, Sumiyoshi-ku, Osaka City, Japan

[Phone number] +81-070-2687-3908

[Fax number $]+81-06-6605-2717$

\begin{abstract}
The benefits and services of urban gardens (UGs) in urbanized areas are being increasingly recognized, leading to widespread enhancement of efforts in protection and provision. At present, several types of UGs created under the policy of "The Garden City Initiative" (GCI) exist in Taipei City, Taiwan, and four types of UGs, namely Allotment Garden (AG), Happy Garden (HG), Rooftop Garden (RG), and School Garden (SG), have been created using vacant lots and rooftop spaces developed via GCI.

To clarify the characteristics of UGs in Taipei City, this paper first analyzes the changes in the number and surface area of each type of UG during 2015-2019. Second, using the 2019 data on all 201 UGs (18 AGs, 107 HGs, and 76 RGs) and excluding SGs that are only accessible by school students, this paper clarifies the spatial distribution of UGs in each district of Taipei City and the accessibility of UGs to locals and non-locals using a geographic information system. Furthermore, correlations between the accessibility of UGs to both locals and non-locals and their surface areas were evaluated. As a result, positive correlation was observed between the accessibility of UGs to locals and non-locals in seven districts, suggesting that both locals and non-locals have equal access to UGs.

Lastly, the characteristics of UGs realized in Taipei City under GCI and their accessibility to locals and non-locals are discussed and conclusions are drawn on the implications for the utilization of vacant lots and rooftop spaces as UGs.
\end{abstract}

Keywords: Geographic Information Systems, Urban Gardening, School Garden, Rooftop Garden 


\section{Introduction}

\subsection{Research background}

In urbanized areas, the benefits and amenity value of natural vegetation in the form of urban gardens (UGs) are gaining widespread recognition, leading to the widespread enhancement of efforts in protection and provision. As convivial spaces, UGs build and nurture the agency of individuals as well as social ties in a community. As inclusive cultural spaces, they can function as a place for cross-cultural learning and understanding as well as for building connections across social and cultural divides. As restorative spaces, UGs contribute to individual and community health and well-being. As democratic spaces, UGs serve as a vehicle to engage individuals and communities in other social and environmental initiatives. As resilient spaces, UGs function as social safety nets and provide for the community in times of calamity and hardship (Jim and Chen 2008; Hou 2017). UGs contribute to resilience in yet another way - through increased capacity for agency and self-organization at the community level. As a space that typically entails the collective contributions of gardeners and volunteers, a UG contributes to community organization and selfhelp. Besides the simple joy of gardening and seeing plants grow, gardeners and volunteers develop and deepen social connections with each other by working together in UGs (Hou 2018).

With the increasing interest in urban agriculture and urban food issues, UGs in the community have become an increasingly welcomed feature of urban landscapes. Reflecting this growing interest and demand, there has been a corresponding shift from temporary occupation of vacant lots to the integration of community gardens into urban park systems. Such integration holds significant opportunities for UGs to achieve stability, expand their overall footprint, and become an integral part of the urban built environment (Hou and Grohmann 2018). Concretely, UGs contribute to community resilience by providing a venue for communication, information sharing, and colearning among diverse gardeners (King 2008). A UG exemplar is the Beach 91st Street Community Garden in New York City; organized by neighbors and gardeners, it provided a staging area for emergency relief after Hurricane Sandy (Hou 2015). Similarly, UGs have been proven to provide social support in terms of providing people a place to go to in times of crisis in Melbourne, Australia (Kingsley and Townsend 2006).

Exploring the potential of UGs has been a recurring phenomenon in different historical contexts worldwide (Hou 2018). For instance, in the United States, previous urban gardening movements have involved efforts to meet the needs of the urban poor (Loggins and Christy 2013) and to address poverty and food shortage during wartime and economic depression (Lawson 2005). Urban gardening has re-emerged as a self-help effort to battle inner-city decline, with the development of garden plots on vacant lots by neighborhood residents since 1960s (Lawson 2004; 2005). Globally, 
increasing attention has been paid to issues of food security, food justice, and urban sustainability, contributing to a resurgence of interest in urban gardening and its broader environmental and social benefits, including urban resilience. In particular, the issue of food security is gaining attention as rapid urbanization has substantially reduced the amount of viable agricultural land; this is accompanied by a renewed scholarly interest in UGs (Guitart et al. 2012; Miller 2015; Padgham et al. 2015; Turner 2011). However, the academic literature on community gardens is dominated by studies investigating gardens in low-income areas with diverse cultural backgrounds or by those based in cities in the USA. In addition, while scholars from a wide diversity of disciplines have examined UGs, research is mostly concentrated in social sciences (Guitart et al. 2012). Moreover, although the fields of urban and environmental planning are notably under-represented, they have a great deal of information to offer, including assessing UG practices to better understand the environmental potential and effects of UGs. In addition, in major Asian cities, such as Taipei City, despite the strong promotion of urban agriculture policies due to the rise in the aging society and the growing demand for urban development, there is still little research on the status of urban farms. Since the launch of the "2010 Taipei International Flower Expo," the Taipei City Government (TCG) has promoted a series of urban regeneration programs to completely change and improve the existing cityscape. The "Beautiful Taipei" series of projects, including eight action plans and three integrated plans, might be the most important turning point for the promotion of the urban agriculture policy in Taipei City today. In this project series, concrete efforts, such as demolishing vacant houses and greening vacant lots as well as vertical greening of the outer walls of schools and public facilities have laid the foundation for today's urban agriculture policy. Against this background, TCG has been promoting its "Garden City Initiative" (GCI) policy that aims to create a sustainable city with increased green space using vacant lots and unused rooftop spaces and by promoting the popularization of "edible landscapes."

At present, four types of UGs-Allotment Garden (AG), Happy Garden (HG), Rooftop Garden (RG), and School Garden (SG) — created using vacant lots and rooftop spaces and developed based on GCI exist in Taipei City, Taiwan (Fig. 1). As Hou (2018) indicated, GCI was introduced in 2015 as a key item on the policy agenda of the then newly elected mayor, Ko Wen-Je. The policy represented a major breakthrough for the nascent urban agriculture movement in Taiwan that was just then gaining traction. The ongoing outcomes of the policy have been remarkable and not least in numbers; the garden sites now range from plazas next to major department stores in high-income commercial areas to small vacant lots in densely populated, older residential neighborhoods. A crucial aspect of UGs in Taipei City is that most of them are built using vacant lots, thereby creating value as a green space. These UGs are multi-functional and considered important vegetation 
resources in each neighborhood and local community in Taipei City today.

\subsection{Research hypothesis, method, and data collection}

Accessibility to urban green spaces (UGSs) has risen as one of the most debated issues in sustainable urban planning, particularly with respect to environmental justice and health inequality. Nevertheless, concerns remain as to whether these disparities in green space access do indeed exist mainly because of the growing recognition of the health and well-being benefits attributable to green spaces. Different people interpret accessibility based on their individual needs and priorities; however, it is generally acknowledged that access to green spaces may be particularly beneficial for children, people in lower socioeconomic groups, and those with mental/psychological illnesses. If accessibility is the measure of the ease of reaching valued destinations, clarifying its definition is an important prerequisite for further analysis aimed at supporting urban planning choices on green spaces (Dai 2011; La Rosa 2014). For example, municipalities across the European Union use different indicators in this area. Some cities provide per capita threshold values for UGS and some have recommendations regarding the minimum distance to a green space, whereas others have no recommendations at all (Kabisch et al. 2016). Focusing on the distance of users to UGs, a parameter that has become important in studies on green spaces in recent years, Yagi (2013) reported that most users resided within $2 \mathrm{~km}$ of a $\mathrm{UG}$ (based on responses to a questionnaire survey to plot users combined with Small Area Statistics of Population Census in Japan).

Taipei City, the capital of Taiwan and its most important economic and political center, has rapidly developed in recent decades, with a congested inner-city filled with densely packed buildings and roads. Scattered green patches mainly contain parks and green road verges. The excessively compact development mode and paucity of green spaces have resulted in a rather poor living environment (Huang et al. 1998). Few studies have been attempted on urban vegetation in Taiwan, particularly in Taipei City, with only scanty information and insights published regarding spatial patterns and variations in species composition in different habitats (Jim and Chen, 2008). In Taipei City, site-specific controversies regarding urban vegetation and green space in urban development challenge planning of evidence-based adaptation. Taipei City illustrates how excessive pragmatism toward how greening is achieved may sideline or obscure justice concerns (Mabon and Shih, 2018). However, no detailed research exists regarding urban vegetation policy, particularly on UGs that are at the core of the latest urban greening strategy in Taipei City, nor have any previous studies evaluated the accessibility of residents to UGs.

The primary objectives of GCI are to realize a sustainable city environment by reducing environmental impacts and creating green space in the form of UGs as places of recreation and relaxation. In addition, UGs are expected to be used by locals and other non-locals that live further 
away (Taipei City Government 2019). Therefore, this paper aimed to evaluate the accessibility of UGs to local people, namely the distance locals must travel to access UGs, and to public transportation to determine the feasibility of UGs in Taipei City for non-locals in the future. According to a report of the Department of Transportation, Taipei City Government (2014), as of 2013, public transportation (41.9\%) was the most commonly used transport for commuting to work and school or for other purposes for Taipei citizens over 15 years of age; it was found to be more commonly used than private transportation (41.1\%) and non-powered transportation (17\%), such as walking or cycling. Meanwhile, city buses and mass-rapid transit (MRT) account for the majority of public transportation at $17 \%$ and $15 \%$, respectively. The public transportation network in Taipei City was primarily established by connecting mid- and long-distance travel based on MRT and connecting short-distance travel using the public rental bicycle system after U-bike was launched in August 2012 in Taipei City (Shiao et al. 2018; Chi et al. 2019; Chang et al. 2019). At present, U-bike has $>12,379$ bicycles operating out of 377 stations, which are installed at the exits of all MRT stations in Taipei City where bus stops are not fully covered. Therefore, this paper assumes that MRT is the main public transportation system in Taipei City for potential users of UGs, namely non-locals.

Based on the above purposes and assumptions, this paper first examines the characteristics of the four types of UGs developed under GCI in Taipei City, utilizing vacant lots and rooftop spaces in the city center that are highly accessible and are equally distributed among all neighborhoods. The characteristic of UGs, including their basic conditions of land property right, a brief evaluation based on demographic information about the users of UGs, change in the area and amount of UGs, and planting patterns have been clarified. Second, this paper focuses on evaluating the accessibility of UG for both locals and non-locals. "The accessibility of UG for locals" refers to the average distance from the border of the local community to the UG, which is important for evaluating whether UGs are equally accessible to all residents within the community. In the case of Taipei City, because the village (里) is the basic unit under each district, this paper calculates the average distance from the boundary of the village where each UG is located to UG. On the other hand, "the accessibility of UG for non-locals" refers to the distance from the UG to the nearest MRT station, which is the primary form of public transportation in Taipei City. Following the definition provided by Kabra et al. (2019), the distance to the nearest MRT stations indicates how far the user must move to reach stations, which is considered a significant factor influencing the willingness of nonlocals to use UGs.

To clarify the characteristics of UGs, this paper first analyzes the changes in the number and surface area of each type of UG during 2015-2019. Furthermore, case evaluation of specific UGs 
is conducted based on data collected from site surveys and latest demographic information derived from the Department of Civil Affairs, Taipei City Government (2020), of the end of 2019 (Section 2). Second, this paper evaluates the accessibility of UGs for both locals and non-locals. Considering that SGs in general do not serve normal citizens, including both locals and non-locals, and that they are used by students within their respective schools, the analysis of this section focuses on all 201 UGs (18 AGs, 107 HGs, and 76 RGs) excluding SGs existing at the end of 2019 (obtained from the open database "Garden city internet platform" operated by TCG) and clarifies the spatial distribution of UGs in each district of Taipei City using a geographic information system (GIS) (QGIS 3.12.0 'București' provided by QGIS Development Team) as well as the correlation between surface areas and accessibility of UGs (Section 3).

\section{Characteristics of each type of urban garden}

\subsection{Basic condition of each type of urban garden}

As mentioned above, there are four types of UGs defined under GCI in Taipei City, which have been summarized in Table 1 and illustrated in Figure 1. AGs are somewhat special among the four types because they are more like a farm and have been promoted long before the garden city policy. In May 1989, the Taipei Farmers Association planned to promote the establishment of a citizen's farm. The farmers' association in the district applied to the Farmers Association of Taipei City and engaged Mr. Wu Jinzheng, a member of the Farmers Association of Beitou District, to create a new concept of urban agriculture. In September 1992, the first and second civic farms were established in Shihlin district. At present, there are 18 AGs in Taipei, and all of them are privately owned.

According to the Taipei City Government (2019), HGs use vacant public land that is offered to community residents and neighborhood groups for adoption; in particular, they are under the care of community volunteers. In addition to planting flowers and plants for greening and beautifying the community environment, various types of fruits and vegetables are cultivated to empower the community, with the promotion of the concept of "sharing." Not only do the volunteers enjoy the crops themselves, but the produce can also be used in community meals or as gifts for disadvantaged minority groups. Edible landscape demonstration areas have been created using vacant public land around the city hall to promote the HG concept. At present, the property rights of HGs include $2.8 \%$ of national land, $15 \%$ of private land, and $82.2 \%$ of public land.

The RG concept promotes public awareness of rooftop vegetable gardens and drives community residents to participate. TCG first selected 12 rooftops of public buildings for RGs. Two of them are combined with the concept of horticultural therapy for use by original social welfare institutions, and the other 10 are open to the community for adoption. To smoothly promote 
RGs and combine the concept of user-designed community creations, TCG recruited community organizations in the vicinity of the building concerned to adopt a RG. At present, $4 \%, 10.5 \%$, and $85.5 \%$ of RGs are nationally, privately, and publicly owned, respectively.

SGs are coordinated by TCG working in concert with public and private schools at all levels (below the university level) in Taipei City. They use vacant land, roofs, platforms, flower terraces, or flower gardens on school campuses. SGs are utilized for various agricultural activities in conjunction with food education and are integrated with relevant courses based on student participation. Of all SGs, $8.2 \%, 1.3 \%$, and $90.5 \%$ are nationally, privately, and publicly owned, respectively.

Because AGs are always intended to be large, full-scale farms located in the suburbs, they do not fit so neatly into the newly established gardens based on recent GCI policies. The other three types (HG, RG, and SG) are the highlights of the GCI policy, with features that are more common and utilizing nearby idle and vacant lots as UGs. By using vacant lots, TCG aims to gradually infiltrate local residential areas by expanding urban farms in cooperation with government agencies. RGs and SGs are aimed at promoting the active use of UGs in the rooftop spaces of public facilities occupied by government agencies or in vacant lots and school rooftop spaces, respectively. HGs are temporary in nature, occupying public land that has been abandoned or private land that has been vacated for redevelopment; management is entrusted to community organizations. In addition, these three types of gardens are at the core of the policy. They are, to all intents, made available free of charge to citizens, unlike AGs. As a result, these three types of gardens have grown in size and number and now far exceed the area of AGs; in addition, HGs and SGs combine to equal an area between twice and thrice that of AGs. In terms of property rights, except for AGs, which are $100 \%$ privately owned, other UGs generally occupy approximately $>80 \%$ of the city-owned public land and approximately $10 \%$ of the privately owned land.

\subsection{Case evaluation based on demographic information}

We use three cases to provide a more concrete understanding of the socioeconomic factors associated with HGs, RGs, and SGs in Taipei City: Case A is Pengcheng HG in Songshan district, Case B is Xinhai Elementary SG in Wunshan district, and Case C is the RG of Taipei City Yongfu for Disabled (RG) in Shihlin district for a brief evaluation as presented in Table 2. In Case A, the private land, which was a parking lot, was converted into a HG in 2015 in response to the request of the local residents and strong community leadership (Urban Village Chief in Taiwan) influencing the landowner. In Case B, the school has been promoting vegetable cultivation by children as part of environmental and dietary education since 2012 and has expanded its SG in response to the GCI policy. Case $\mathrm{C}$ is a public support facility for people with disabilities. The 
consigned social welfare organization sympathized with GCI's concept of a sustainable ecological environment and converted its rooftop space into a RG in 2015. All of the above cases were selected as representative cases that started in 2015, which was the first year of GCI.

As shown in Table 2, the population composition of each community (Urban Village in Taiwan) in which the three cases are located is similar, with a young population of individuals aged 0-14 years accounting for approximately $10 \%-15 \%$ of the population, a production population comprising individuals aged 15-64 years accounting for approximately 60\%-70\%, and the elderly population aged $>65$ years accounting for $15 \%$. However, the age composition of UG users substantially varies from case to case, and each of them significantly differs from the existing population composition in each community where each case is located. In Case A, elderly people aged $>65$ years accounted for approximately $80 \%$ of all UG users, whereas in Case B, young people aged $<14$ years accounted for $>90 \%$ of all UG users because the garden is situated at an elementary school. Because the welfare facility of Case C is only for users aged 15-64 years old, this population accounts for $>90 \%$ of all UG users.

Evaluation of population demographic information and the area occupied by the community and UGs (Table 3) shows that the proportion of land occupied by UGs is not $>1 \%$ of the area of land occupied by the community in each case, whereas the participation ratio, which is the percentage of UG users out of the total population of each community, is approximately $4.7 \%$ 12.1\%. In particular, in Cases A and C, almost 1 of every 10 people in the community is a UG user. These findings indicate that the local participation in UGs has spread in the communities to a certain extent. However, the area occupied by UGs is extremely small compared with that occupied by the community.

On the other hand, the participation ratio of the locals is only around $12.1 \%$ at the highest, and there is room for further increase in the future while the use of UGs by non-locals is not clear so far. By clarifying the situation of the spatial distribution of UGs and the accessibility of UGs to locals and non-locals by this paper, and showing the situation whether the UGs are easily accessible to many citizens, it will become an important clue for promoting the use of UGs by both locals and non-locals in the future.

\subsection{Growth trends of UGs}

The number and proportions of the four types of gardens during 2015-2019 are illustrated in Figure 2. The number of SGs has been steadily increasing since 2015; they now account for $73 \%$ of the four garden types. The number of RGs increased until 2018 and then dropped sharply to leave them accounting for only $10.3 \%$ of all garden types. HGs have increased slowly but steadily since 2019 , accounting for $14.3 \%$ of the total. As mentioned above, because AGs are not at the 
core of the GCI, their increase has been consistently small, currently comprising only $2.4 \%$ of the four types.

The change in the area covered by the four types of gardens during 2015-2019 is illustrated in Figure 3. The area of SGs has steadily grown and now stands at $89,735 \mathrm{~m}^{2}$ and accounts for $46.2 \%$ of the total area of the four types of gardens. Therefore, while $73 \%$ of the gardens are SGs, the area they occupy is $<50 \%$, indicating the area per garden is small. The area occupied by HGs has also consistently grown to $56,482 \mathrm{~m}^{2}(29.1 \%)$. Given that HGs constitute $14.3 \%$ of gardens, it can be said that the area per garden is relatively large. The area occupied by AGs has changed little $(21,487$ $\mathrm{m}^{2}$ at present), and although they account for only $2.4 \%$ of the four types of gardens, they account for $13.7 \%$ of the total area, thereby leading to the inference that the area per allotment is large. The average areas $\left(\mathrm{sm}^{2}\right)$ of each garden type in descending order are as follows: $\mathrm{AG}, 1,474 \mathrm{sm}^{2} ; \mathrm{HG}$ $538 \mathrm{sm}^{2}$; RG $283 \mathrm{sm}^{2}$; and SG $167 \mathrm{sm}^{2}$.

The above analysis indicates that the four types of UGs developed under GCI have different characteristics and that the number and size of each garden are quite different. SGs have the smallest average area, but they are more in number than any other type. In addition, their combined area is the largest of all gardens. Because SGs are located on school grounds, they are most likely to exist in every region and community of Taipei City; therefore, they are expected to play a role as the closest and most intimate UG for Taipei City residents.

The planting patterns for each type of UG are shown in Figures $4 \& 5$. The main planting patterns can be divided into ground planting, potted planting, both of these (mixed use of ground and potted planting, referred to as "mixed" below), and "other" (mainly hydroponics and vertical cultivation). AGs, being large, full-scale gardens, are $66.7 \%$ ground planting and $33.3 \%$ potted planting. In the case of HGs, 54.2\% use mixed planting, while $32.7 \%$ use ground planting, a combination that can be explained on the basis that HGs constitute a provisional use prior to future redevelopment; therefore, a more flexible usage is assumed. In RG, the pattern is $\sim 45 \%$ for each of the mixed and potted planting. Because RGs use rooftop space, potted planting is predominant compared with ground planting. SGs use both rooftop and vacant lots fully, with gardens benefiting from students' ingenuity; subsequently, the planting pattern is entirely "mixed."

\section{Result: Evaluation of the spatial distribution and accessibility of each type of UG}

\subsection{Distribution of UGs in each district: focus on number and size}

There is a large variation in the area occupied by each type of UG in each district (Table 4). Focusing on the average surface area of the various UGs in each district, of the five districts having AGs, those in Beitou cover the largest area by far $\left(3,000 \mathrm{~m}^{2}\right)$; approximately five times that in 
Nangang district. The average RG is very small $\left(<100 \mathrm{~m}^{2}\right)$ in Nangang and Jhongshan districts compared with the overall average $\left(249 \mathrm{~m}^{2}\right)$, whereas the average in Songshan district is $787 \mathrm{~m}^{2}$, approximately three times the overall average. Regarding HGs, the overall average is $425 \mathrm{~m}^{2}$, while the lowest average is $130 \mathrm{~m}^{2}$ in Wanhua District and the highest is in Beitou and Sinyi districts (>900 $\mathrm{m}^{2}$, approximately twice the overall average).

Beitou district has the largest total surface area of UGs (approximately 25,119 $\mathrm{m}^{2}$ ) and greatly exceeds the total surface area of $15,296 \mathrm{~m}^{2}$ of Shihlin district, which is the second place in Taipei City. Even when focusing on the average surface area per UG, Beitou district has the largest surface area at $1,142 \mathrm{~m}^{2}$ per UG, which is approximately 10 times the area of Wanhua district $\left(125 \mathrm{~m}^{2}\right)$. Overall, the districts that exceed the total surface area of the 12 districts of 7,992 $\mathrm{m}^{2}$ are Shihlin, Beitou, and Sinyi districts, and those that exceed the average surface area per UG of $463 \mathrm{~m}^{2}$ of 12 districts are Shihlin, Beitou, Sinyi, Nangang, and Songshan districts. In actuality, as shown in the box-and-whisker plot in Figure 6, the total surface area of UGs constitutes $<1,000 \mathrm{~m}^{2}$ in all districts, except Beitou and Songshan districts, and there are many outliers (UGs with extreme values) in the Beitou, Shihlin, and Sinyi districts. Taken together, because many UGs exist in Shihlin, Beitou, and Sinyi districts, these districts can be regarded to be of extreme value for the surface area of UGs. On the other hand, it can be concluded that the total surface area of UGs and the average surface area per UG are not very different.

\subsection{Evaluation of accessibility of UGs to locals and non-locals}

In this paper, all $201 \mathrm{UG}$ projects were plotted on a map using GIS using the coordinates acquired by inputting the addresses of all the UGs into Google Maps. First, to evaluate the accessibility of UGs to locals, this paper assumed the distance that locals must travel to use UGs as the "accessibility of UGs to locals." For calculating the distance locals must travel to the UG of each village, the boundary of each village is extracted as points every $500 \mathrm{~m}$, and the average distance from each point to the UG is calculated by referring to the available literatures regarding the evaluation of accessibility of green space (Nicholls 2001; Pearce et al. 2006; Coutts 2008).

On the other hand, to evaluate the accessibility of UGs to non-locals, this paper assumed the distance that non-locals must travel from MRT stations to UGs as the "accessibility of UG to nonlocals." For calculating the above distance, previous research related to accessibility of MRT (Cervero et al. 2009; Tillmann et al. 2018; He et al. 2018) and to assistance in the analysis of accessibility of UG were accumulated as well as buffer zones of $500 \mathrm{~m}$ in diameter around each MRT station in each district of Taipei City were plotted. The distance of each type of UG in each district to the nearest MRT station was calculated using GIS (Fig. 7).

The box-and-whisker plot in Figure 8 shows that the accessibility of UGs to locals in each 
district was generally around the 500-m range, except for those in Beitou, Shihlin, Nangang, and Wunshan districts, where the distance was around $1,000 \mathrm{~m}$. On the other hand, the accessibility of UGs to non-locals was also generally over the 500-m range from stations, except for Datong and Nangang districts. Furthermore, in Beitou, Shihlin, Wanhua, and Wunshan districts, the accessibility of UGs to non-locals was more than $1,000 \mathrm{~m}$; thus, they were deemed as quite inaccessible.

\subsection{Correlation between UG area and accessibility to locals and non-locals}

Next, to further verify the spatial distribution of UGs based on the accessibility to both locals and non-locals, this paper aimed to discover any correlation between the accessibility of UGs to both locals and non-locals and their surface area in each district. Three examinations using correlation analysis were performed using the Pearson product-moment correlation coefficient by treating all three types of UGs as a single group: first examination, correlation between (1) accessibility of UGs to locals and (2) accessibility of UGs to non-locals in each district; second examination, correlation between (1) accessibility of UGs to locals and (3) surface area of UGs in each district; third examination, correlation between (2) accessibility of UGs to non-locals and (3) surface area of UGs in each district. Table 5 shows the correlation coefficient ( $R$ values) for each district of the above three examinations.

For the first examination, the R values for Nangang, Shihlin, Beitou, Songshan, Neihu, Wunshan, and Sinyi districts were $0.782,0.782,0.731,0.687,0.506,0.431$, and 0.347 , respectively, indicating strong positive correlations between accessibility of UGs to locals and that of non-locals. These values suggest that accessibility to UGs in these areas changes in a similar direction for both local and non-locals. Concretely, because all these districts are located in the suburbs, it is considered that the UGs in these districts tend to be located almost equally far from the center of each village (accessibility to locals) and from the MRT station (accessibility to non-locals) in each district. In other words, it is possible for these districts to promote the use of UGs for both locals and nonlocals under the same condition of accessibility. On the other hand, Da'an and Jhongshan districts showed a negative correlation $(R=-0.434$ and -0.209 , respectively). In these districts, the accessibility of UGs to locals changes in the opposite direction to that to non-locals. These values reflect the characteristics of these districts: the further away from the center part of the village where larger areas can be secured for UGs.

For the second examination, the $R$ values for Beitou, Wunshan, Sinyi, Shihlin, and Jhongjheng districts were $0.392,0.367,0.299,0.295$, and 0.250 , respectively, indicating positive correlations between the accessibility of UG to non-locals and UG surface area. These values reflect the characteristics of these districts: UGs were located further away from the center of the village where 
larger areas can be secured. On the other hand, Da'an districts showed a negative correlation, with a $\mathrm{R}$ value of -0.252 . This indicates that it is possible to secure a larger area for UGs in the center of the village rather than away from the center of village. However, there was little correlation in other districts.

For the third examination, the R values for Beitou, Da'an, Shihlin, Songshan, Datong, and Wunshan districts were $0.672,0.522,0.449,0.407,0.386$, and 0.216 , respectively, indicating positive correlations between the accessibility of UGs to non-locals and the surface area. Although Da'an and Datong districts are located in the center of the city and Beitou, Shihlin, Songshan, Datong, and Wunshan districts are located in the suburbs, the accessibility to the MRT station is similar. These values reflect the characteristics of these districts: UGs were located further away from MRT stations where larger areas can be secured. However, there was little correlation in other districts.

\section{Discussion}

This paper confirms the TCG's aggressive promotion of UGs in Taipei City, as evidenced by the rapidly increasing cases and surface area of UGs under the GCI policy. Using various types of vacant public land and other space is the easiest way to provide urban vegetation to communities and residents. Because UGs are mainly operated and managed by community residents, they are considered an important factor that encourages citizen participation in Taipei City. At present, there are large differences in the characteristics of UGs between the downtown and suburban areas of Taipei City, particularly in terms of surface area, number, and accessibility. Correlation analysis has confirmed that, for the three types of UGs together when SGs are excluded, UGs can secure a relatively large area as the distance from the nearest MRT station increases. Furthermore, strong positive correlations between accessibility of UGs to locals and non-locals were verified, suggesting the possibility for both locals and non-locals to access UGs equally. In addition, owing to the high accessibility of UGs to both locals and non-locals in all except some districts, namely Beitou, Shihlin, and Wunshan, and considering the purpose of GCI, it might be desirable to increase the number of potential non-local UG users who use public transportation by actively opening UGs that are currently mainly used by locals.

Based on the experience of Taipei City, there is a need to formulate a sufficiently funded policy involving the positive utilization of vacant public lands rather than to the acquiring private land for the development of UGs. In addition, the mission of UGs is not only to promote greening and environmental improvement but also to promote the social participation of community residents, to construct edible landscapes using green spaces in local communities, and to provide facilities 
for social and food education. On the other hand, when considering equal opportunities for locals and non-locals, it is considered essential to secure vacant lots or spaces with desirable locational characteristics as public facilities, such as SGs for the provision of UGs. By ensuring the high accessibility of UGs via connection and cooperation with public transportation, as in the case of Taipei City, it is possible to encourage their use and exploit the beneficial effects of UGs on social participation. In addition, it is found that the demographics of current UG users are different from the population composition of each region and that the participation ratio has room for growth. We believe that these problems can be solved by promoting the more universal use of UGs, making them available to more non-locals for diversification and make-up of gardeners, and stimulating community participation.

This paper has some limitations. First, the methods used secondary data vis-à-vis primary data collected through surveys and interviews. Furthermore, although the characteristics of UGs created used vacant lots and rooftop spaces have been clarified, they are not distinguished or discussed in both data and analysis. Therefore, further analysis regarding the distinction between UGs using vacant lots and those using rooftop spaces is warranted. Finally, further verification regarding the correlation between their proximity to public transportation, including MRT stations and bus stops, and the actual make-up of the gardeners, including both locals and non-locals, might be important issues for future studies.

\section{Funding}

This paper is supported by a part of grants (Number 19K15174) from the Japan Society for the Promotion of Science (JSPS).

\section{Conflicts of interests/Competing interests}

The author has no conflict of interest.

\section{Corresponding author}

Correspondence to Hongwei HSIAO.

\section{Acknowledgments}

The author thanks for the support of JSPS and the data provision from Taipei City Government. The experiments comply with the current laws of the country in which they were performed. The author would like to thank Enago (www.enago.jp) for the English language review. 


\section{References}

Cervero R, Sarmiento OL, Jacoby E, Gomez LF, Neiman A (2009) Influences of built environments on walking and cycling: Lessons from Bogotá. Int J Sustain Transp 3:203-226

Chang SKJ, Chen HY, Chen HC (2019) Mobility as a service policy planning, deployments and trials in Taiwan. IATSS Research 43:210-218

Chi CF, Chen PL, Saleh W, Tsai SH\& Pai CW (2019) Helmet non-use by users of bikeshare programs, electric bicycles, racing bicycles, and personal bicycles: An observational study in Taipei, Taiwan. Int J Sustain Transp 13(2):93-99

Coutts C (2008) Greenway accessibility and physical-activity behavior. Environ Plann B: Plann Des 35:552-563

Dai D (2011) Racial/ethnic and socioeconomic disparities in urban green space accessibility: Where to intervene? Landsc Urban Plan 102:234-244

Department of Civil Affairs, Taipei City Government (2020) Population of each urban village, https://ca.gov.taipei/News_Content.aspx?n=8693DC9620A1AABF\&sms=D19E9582624 D83CB\&s=EE7D5719108F4026

Department of Transportation, Taipei City Government (2014) Report on the analysis of residential or commuting trips of citizens over 15 years old in Taipei City.

Guitart D, Pickering C, Byrne J (2012) Past results and future directions in urban community gardens research. Urban For Urban Greening 11:364-373

He Y, Zhao Y, Tsui KL (2018) An analysis of factors influencing metro station ridership: Insights from Taipei metro. 2018 21st International Conference on Intelligent Transportation Systems (ITSC), Maui, HI, pp 1598-1603

Hou J (2015) Guerrilla resilience. In: Hoffman Brandt D, Seavitt Nordensen C (eds) Waterproofing New York, Urban Research (UR) 2. Terreform, New York, pp 90-99

Hou J (2017) Urban community gardens as multimodal social spaces. In: Tan P, Jim C (eds) Greening cities. Advances in 21st century human settlements. Springer, Singapore.

Hou J (2018) Governing urban gardens for resilient cities: Examining the 'Garden City Initiative' in Taipei. Urban Stud 2018:1-19

Hou J, Grohmann D (2018) Integrating community gardens into urban parks: Lessons in planning, design and partnership from Seattle. Urban For Urban Greening 33:46-55

Huang SL, Wong JH, Chen TC (1998) A framework of indicator system for measuring Taipei's urban sustainability. Landsc Urban Plan 42:15-27

Jim CY, Chen WY (2008) Pattern and divergence of tree communities in Taipei's main urban green spaces. Landsc Urban Plan 84:312-323 
Kabisch N, Strohbach M, Haase D, Kronenberg J (2016) Urban green space availability in European cities. Ecol Indic 70:586-596

Kabra A, Belavina E, Girotra K (2019) Bike-Share Systems: Accessibility and Availability. Management Science 66:3803-3824

King C (2008) Community resilience and contemporary agri-ecological systems: Reconnecting people and food, and people with people. Syst Res Behav Sci 25: 111-124

Kingsley JY, Townsend M (2006) 'Dig in' to social capital: Community gardens as mechanism for growing urban social connectedness. Urban Policy Res 24:525-537

La Rosa D (2014) Accessibility to greenspaces: GIS based indicators for sustainable planning in a dense urban context. Ecol Indic 42:122-134

Lawson L (2004) The planner in the garden: A historical view into the relationship between planning and community gardens. J Plan Hist 3:151-176

Lawson L (2005) City bountiful: A century of community gardening in America. University of California Press, Berkeley

Loggins D, Christy L (2013) History of New York City open space. Commun Greening Rev 18:1419

Mabon L, Shih WY (2018) What might ‘just green enough’ urban development mean in the context of climate change adaptation? The case of urban greenspace planning in Taipei Metropolis, Taiwan. World Dev 107:224-238

Miller WM (2015) UK allotments and urban food initiatives: (Limited?) potential for reducing inequalities. Local Environ 20:1194-1214

Padgham J, Jabbour J, Dietrich K (2015) Managing change and building resilience: A multi-stressor analysis of urban and peri-urban agriculture in Africa and Asia. Urban Climate 12:183-204

Pearce J, Witten K, Bartie P (2006) Neighbourhoods and health: a GIS approach to measuring community resource accessibility. J Epidemiol Community Health 60:389-395.

Nicholls S (2001) Measuring the accessibility and equity of public parks: a case study using GIS. Managing Leisure 6:201-219

Shiao YC, Chung WH, Chen RC (2018) Using SVM and Random forest for different features selection in predicting bike rental amount. 2018 9th International Conference on Awareness Science and Technology (iCAST), Fukuoka, 2018: 1-5

Taipei City Government (2019) Garden city internet platform. https://farmcity.Taipei City/m0/index.php

Tillmann S, Clark AF, Gilliland JA (2018) Children and nature: Linking accessibility of natural environments and children's health-related quality of life. Int J Environ Res Public Health 
$15: 1072$

Turner B (2011) Embodied connections: Sustainability, food systems and community gardens. Local Environ 16:509-522

Yagi H (2013) Site Location and demand for the farm experience business in urban areas. J Rural Plan Assoc 32:323-328 
Figure

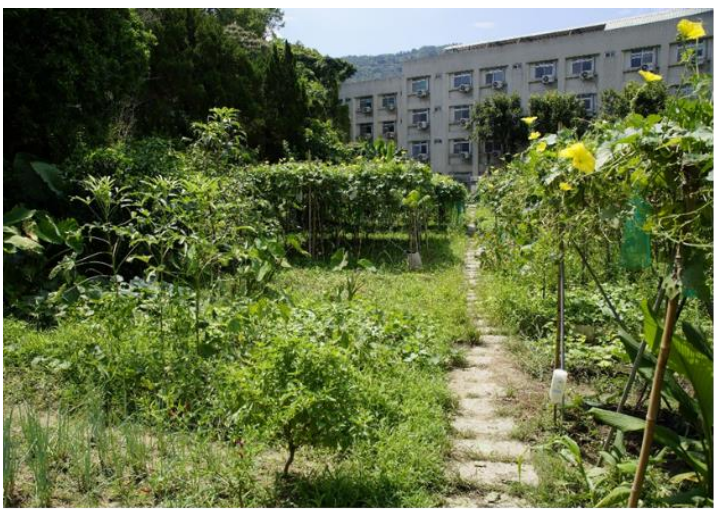

Allotment Garden (AG)

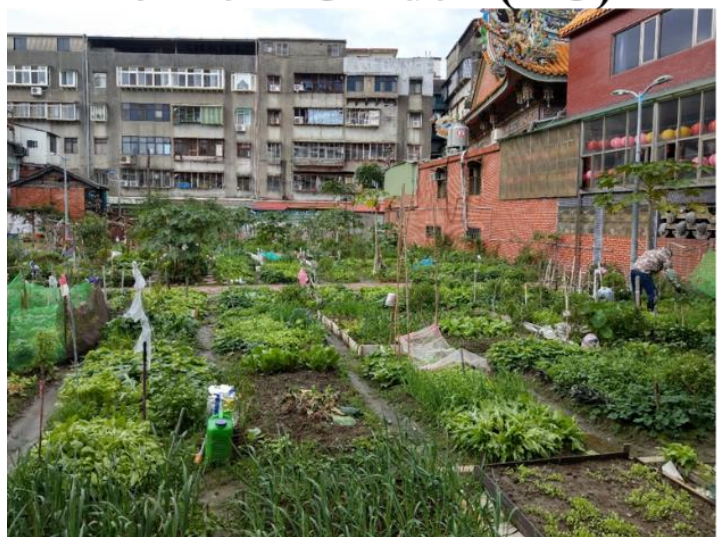

Happy Garden (HG)

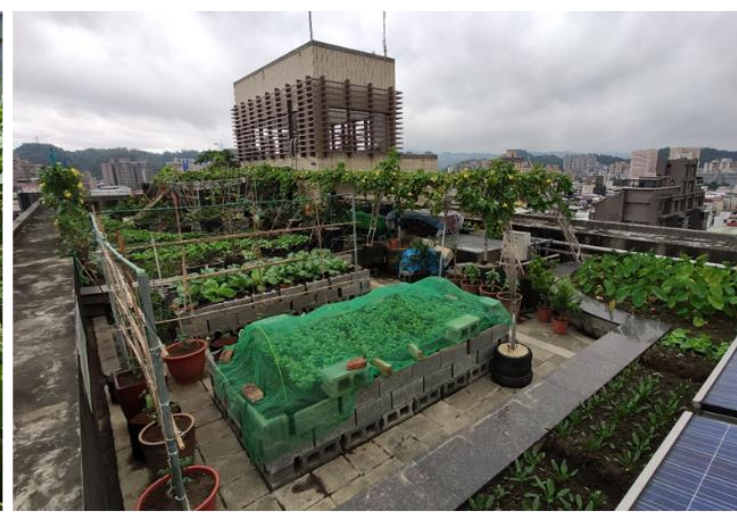

Rooftop Garden (RG)

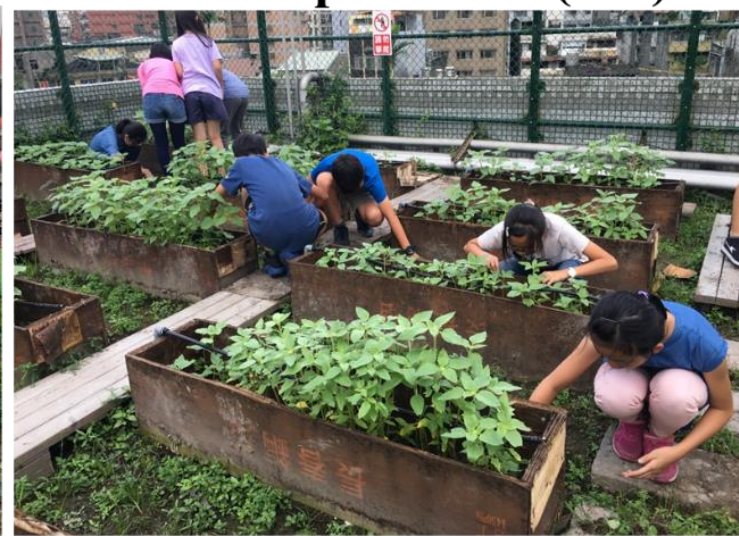

School Garden (SG)

Fig. 1 Examples of each type of UG 


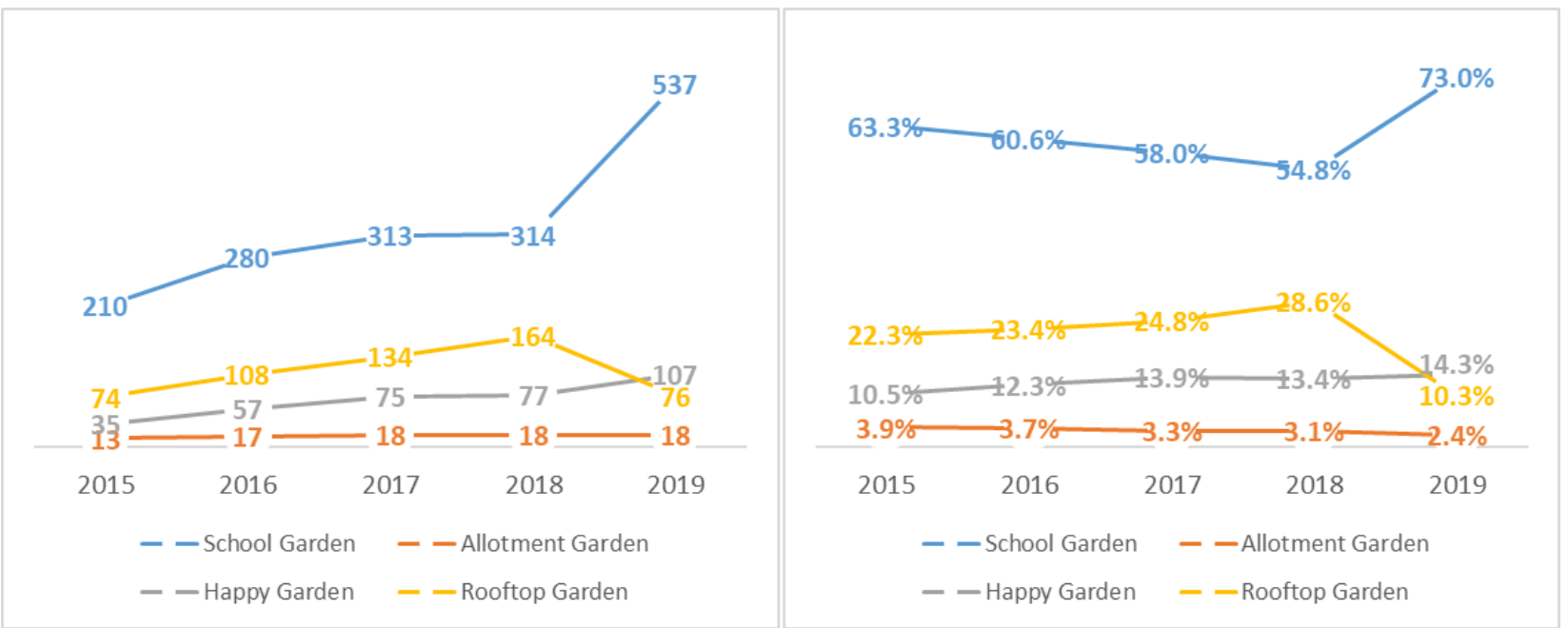

Fig. 2 Changes in the number (left) and proportion (right) of each type of UG 2015-2019 


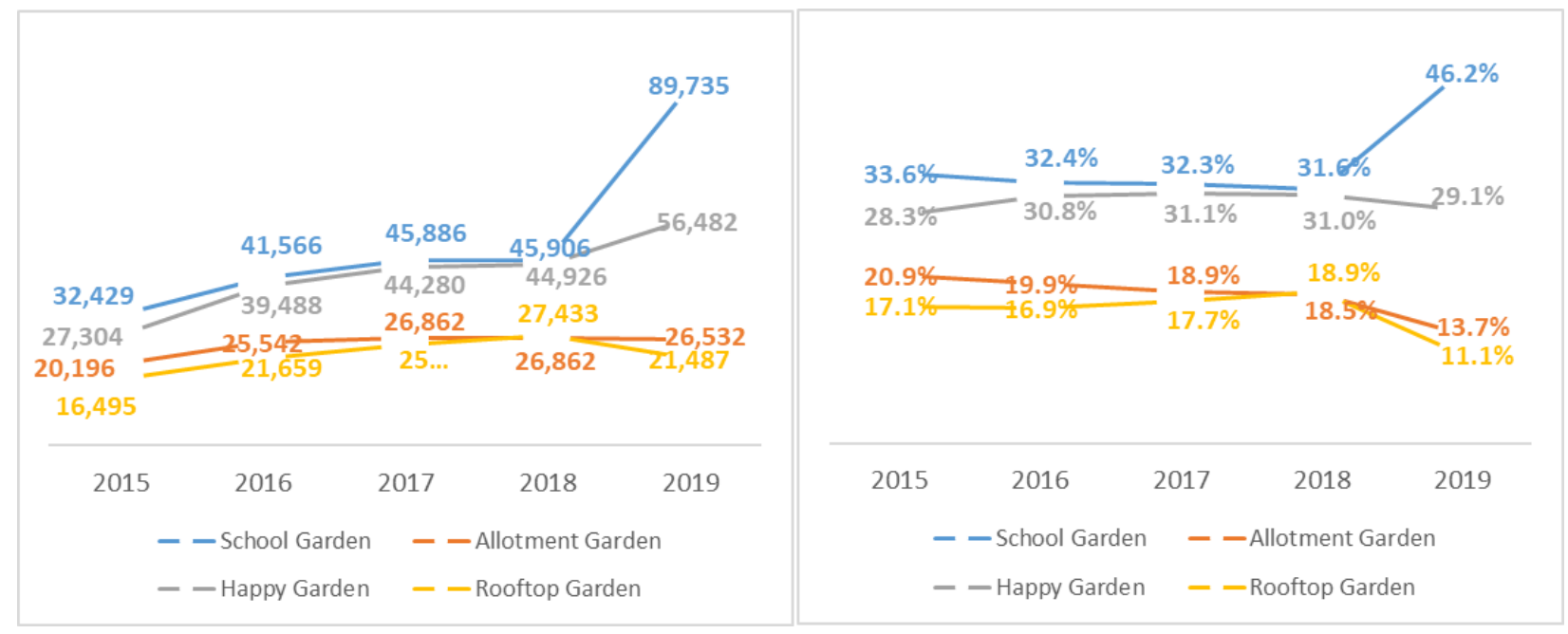

Fig. 3 Changes in the absolute area (left; $\mathrm{m}^{2}$ ) and proportion of area (right) occupied by each type of UG 2015-2019 


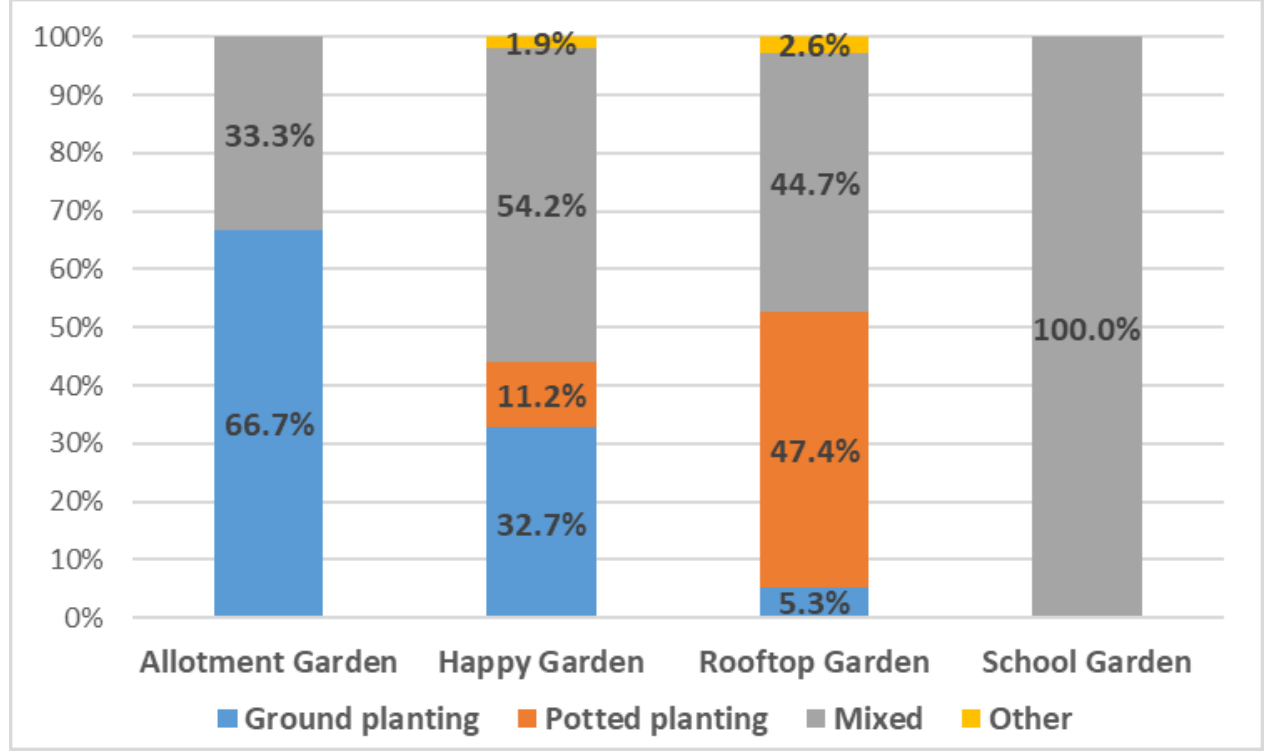

Fig. 4 Planting pattern proportions for each type of UG 


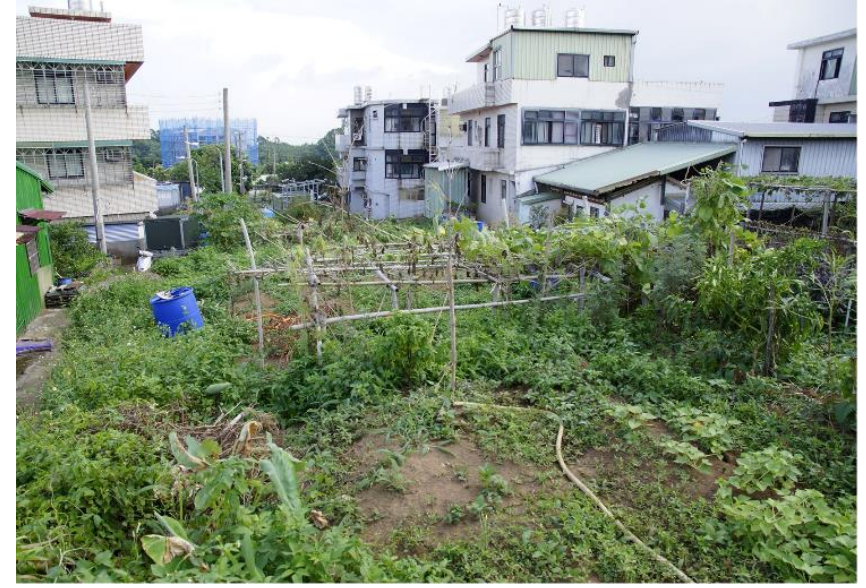

Ground Planting (a case of AG)

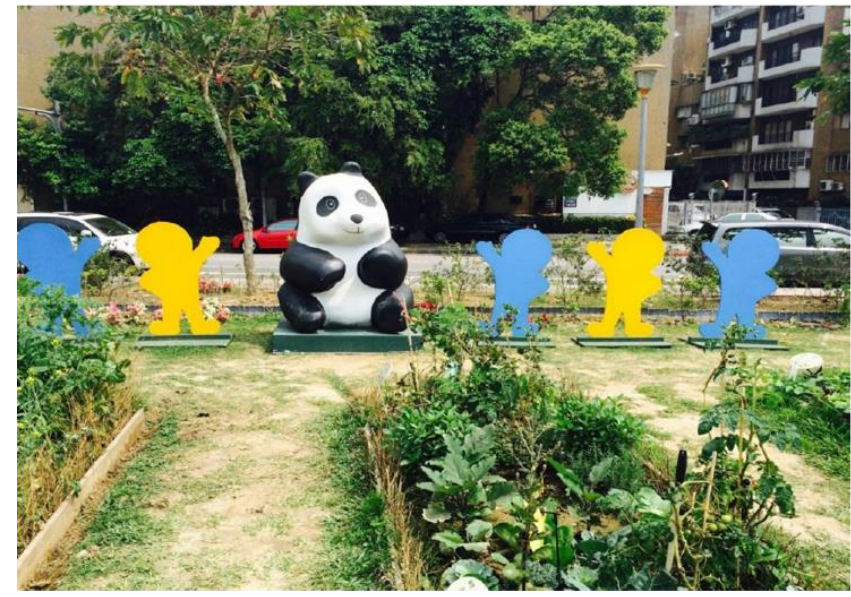

Mixed (a case of HG)

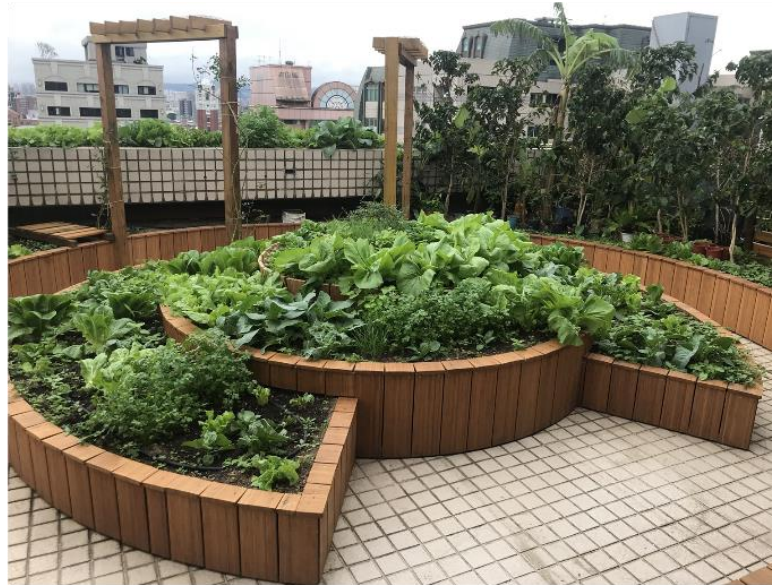

Potted planting (a case of RG)

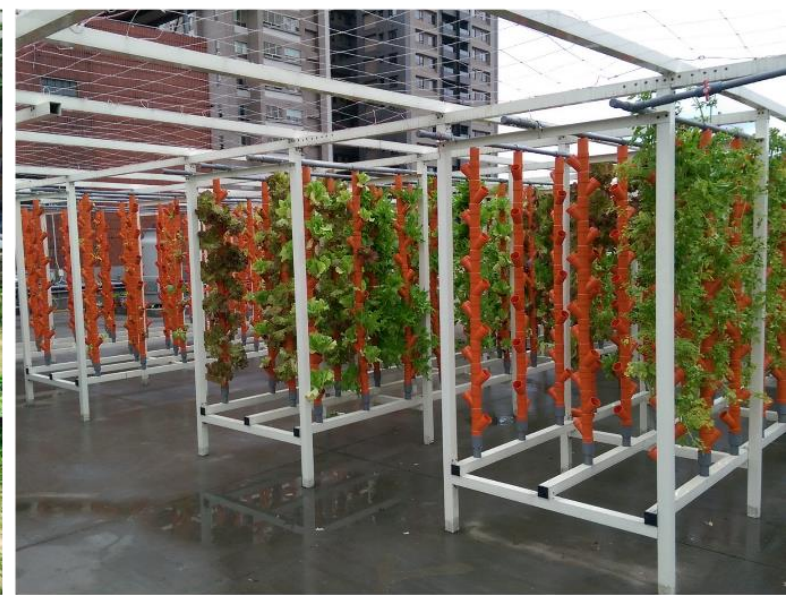

Other (a case of RG)

Fig. 5 Typical examples of each planting pattern of each type of UG 


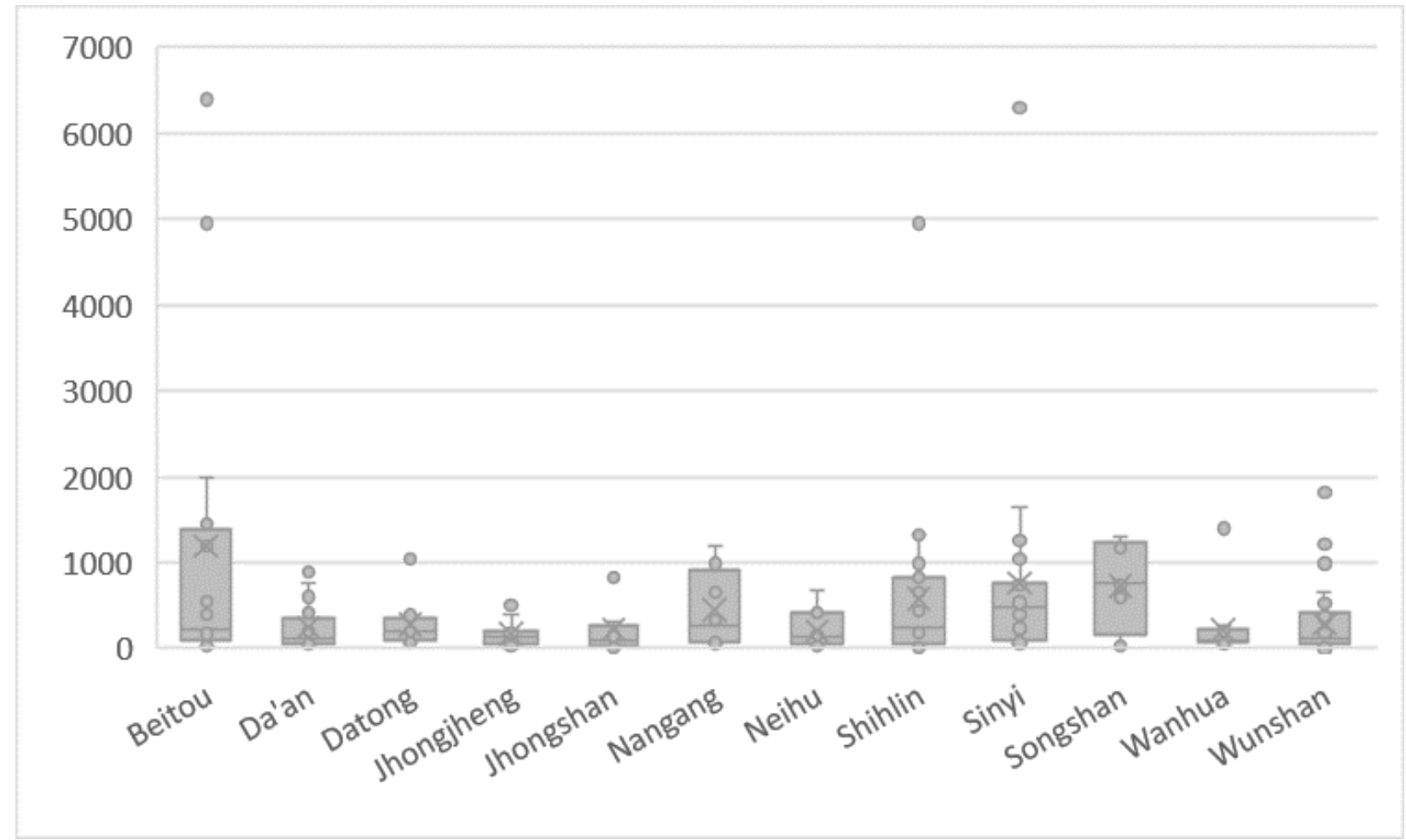

Fig. 6 Box-and-whisker plot for the total surface area $\left(\mathrm{m}^{2}\right)$ of UG in each district in Taipei City 


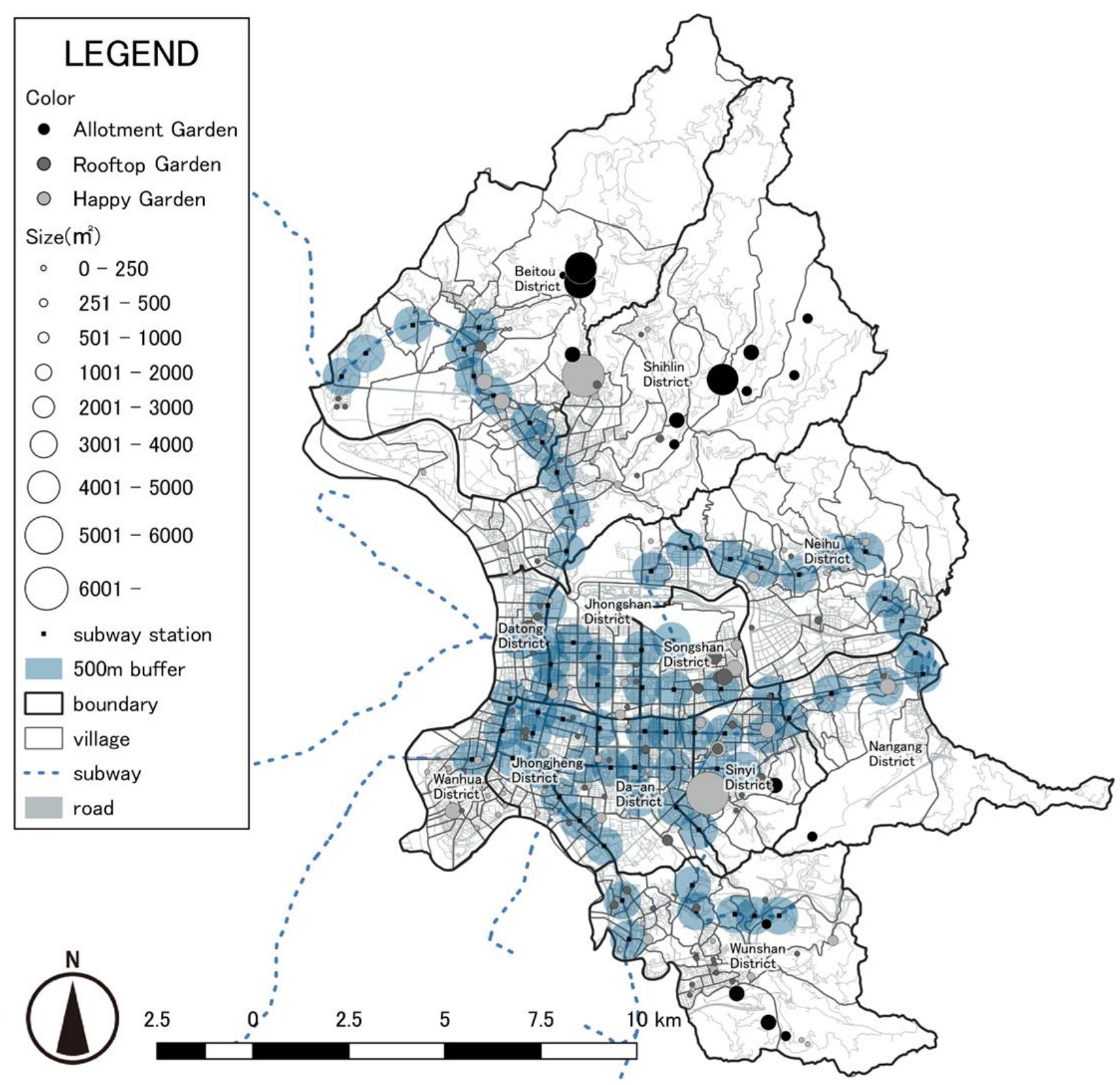

Fig. 7 Distribution of UG by type and area $\left(\mathrm{m}^{2}\right)$ plotted on a map of Taipei City alongside MRT stations marked with 500-m diameter buffer zones and the boundary of village 


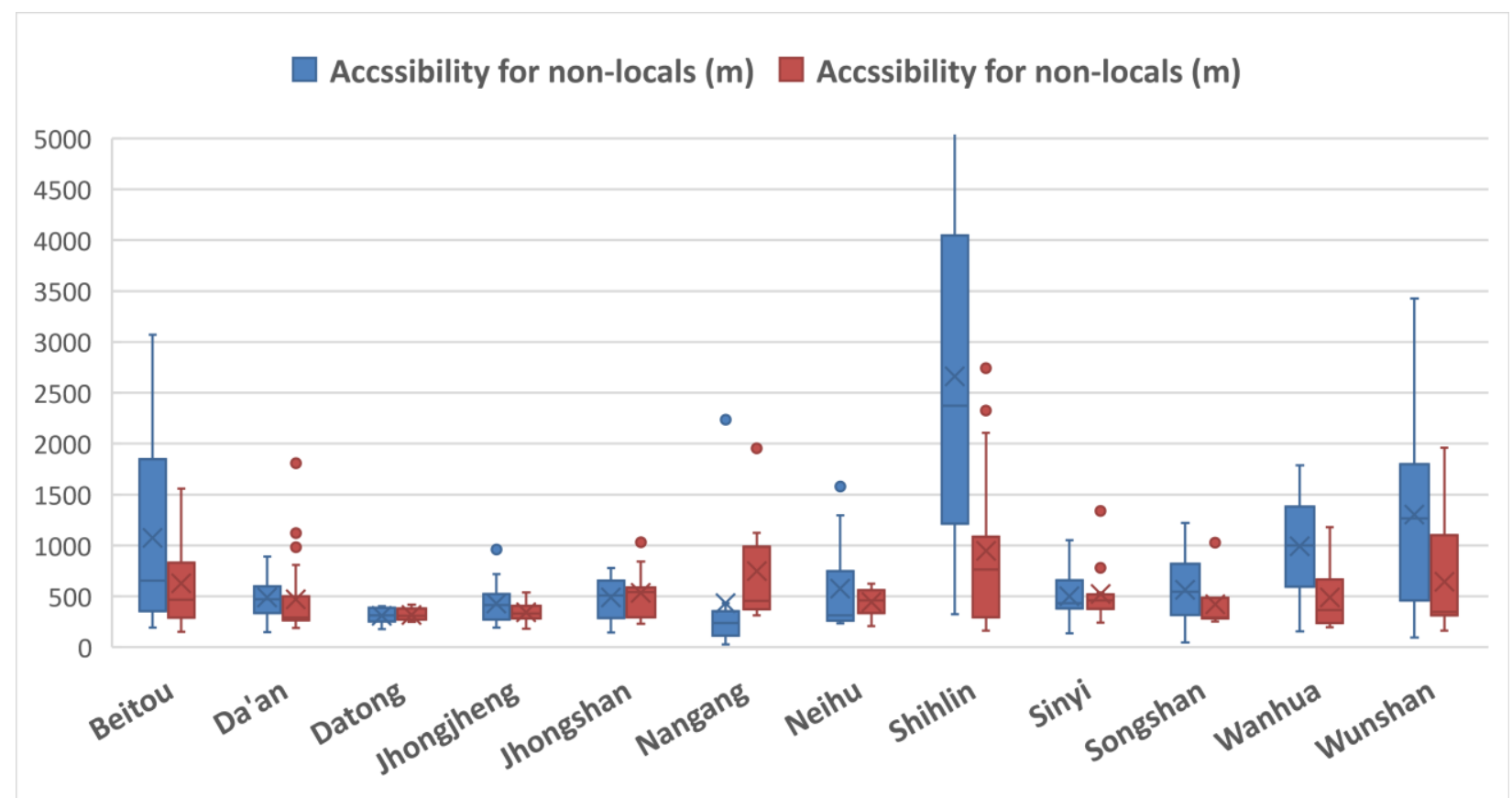

Fig. 8 Box-and-whisker plot for the accessibility (m) of UG to locals and non-locals in each district in Taipei City 


\section{Tables}

2

3 Table 1. Research target: four types of urban gardens in Taipei City

\begin{tabular}{|c|c|c|c|c|}
\hline & $\mathbf{A G}$ & HG & RG & SG \\
\hline Location & $\begin{array}{c}\text { Existing } \\
\text { gardens or farms } \\
\text { in Taipei City }\end{array}$ & $\begin{array}{c}\text { Public or private } \\
\text { vacant lots }\end{array}$ & $\begin{array}{l}\text { Vacant rooftops } \\
\text { of public facilities }\end{array}$ & $\begin{array}{l}\text { Vacant lots at } \\
\text { school facilities }\end{array}$ \\
\hline Users & Registered users & Local residents & Local residents & Students \\
\hline Management & $\begin{array}{l}\text { Owner of } \\
\text { garden }\end{array}$ & $\begin{array}{l}\text { Community } \\
\text { organization }\end{array}$ & \multicolumn{2}{|c|}{$\begin{array}{c}\text { The authority of each public facility } \\
\text { or school facility }\end{array}$} \\
\hline Fee & Charged & Free & Free & Free \\
\hline Number & 18 & 107 & 76 & 537 \\
\hline $\begin{array}{l}\text { Property right } \\
\text { (calculated by } \\
\text { number of } \\
\text { cases) }\end{array}$ & Private: $100 \%$ & $\begin{array}{c}\text { National: } 2.8 \% \text {, } \\
\text { Private: } 15 \% \\
\text { Public (Taipei } \\
\text { City): } 82.2 \%\end{array}$ & $\begin{array}{c}\text { National: } 4 \% \text {, } \\
\text { Private: } 10.5 \% \\
\text { Public (Taipei } \\
\text { City): } 85.5 \%\end{array}$ & $\begin{array}{c}\text { National: } 8.2 \% \text {, } \\
\text { Private: } 1.3 \% \\
\text { Public (Taipei } \\
\text { City): } 90.5 \%\end{array}$ \\
\hline
\end{tabular}

4 
Table 2. Demographic data of three cases of HG, SG and RG selected of the end of 2019

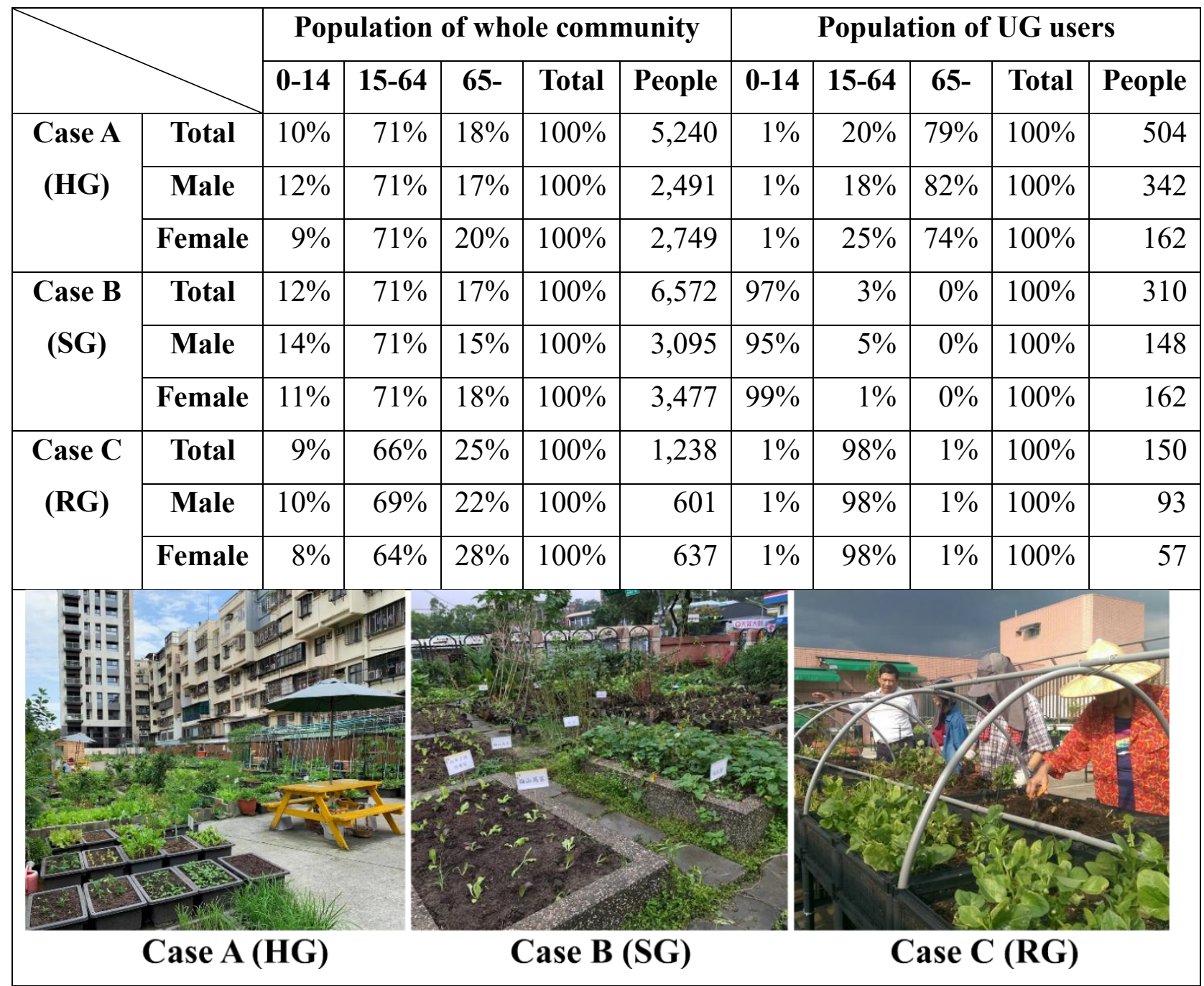

8 Note: population data of whole community of each cases is acquired from Department of Civil

9 Affairs, Taipei City Government (2020), while population data of each case is calculated based

10 on the interviews with each case and the information obtained from them. 
12 Table 3. Brief evaluation of three cases selected based on socio-economic aspects

\begin{tabular}{|c|c|c|c|c|c|c|}
\hline & \multicolumn{2}{|c|}{$\begin{array}{r}\text { Total area (m2) (a), } \\
\text { population (people) } \\
\text { (b) of community }\end{array}$} & \multicolumn{2}{|c|}{$\begin{array}{l}\text { Total area }(\mathrm{m} 2)(\mathrm{c}), \mathrm{u} \\
\text { sers (people) (d) of } U\end{array}$} & $\begin{array}{r}\text { Area ratio } \\
\text { (c) } /(\mathbf{a}) * 100 \%\end{array}$ & $\begin{array}{r}\text { Participation } \\
\text { ratio } \\
(d) /(b) * 100 \%\end{array}$ \\
\hline Case $\mathrm{A}(\mathrm{HG})$ & 123,000 & 5,240 & 1,176 & 504 & $1.0 \%$ & $9.6 \%$ \\
\hline Case B (SG) & 573,300 & 6,572 & 389 & 310 & $0.1 \%$ & $4.7 \%$ \\
\hline Case C (RG) & $1,371,500$ & 1,238 & 276 & 150 & $0.02 \%$ & $12.1 \%$ \\
\hline
\end{tabular}

13 
14 Table 4. Number and Total surface area (m2) and Average surface area (m2) of each type of UG 15 in each district in Taipei City, 2019

\begin{tabular}{|c|r|r|r|r|r|r|r|r|r|r|r|r|}
\hline District & \multicolumn{3}{|c|}{ AG } & \multicolumn{3}{|c|}{ RG } & \multicolumn{3}{c|}{ HG } & \multicolumn{3}{c|}{ Total } \\
\hline Wunshan & 4 & 4,356 & 1,089 & 17 & 2,957 & 174 & 13 & 2,634 & 203 & 34 & 9,947 & 293 \\
\hline Shihlin & 8 & 11,880 & 1,485 & 9 & 1,330 & 148 & 9 & 2,086 & 232 & 26 & 15,296 & 588 \\
\hline Beitou & 4 & 12,276 & 3,069 & 6 & 1,174 & 196 & 12 & 11,669 & 972 & 22 & 25,119 & 1,142 \\
\hline Da'an & 0 & - & - & 8 & 2,733 & 342 & 13 & 2,389 & 184 & 21 & 5,122 & 244 \\
\hline Neihu & 0 & - & - & 5 & 710 & 142 & 5 & 1,475 & 295 & 10 & 2,185 & 219 \\
\hline Sinyi & 0 & - & - & 7 & 2,622 & 375 & 13 & 11,836 & 910 & 20 & 14,458 & 723 \\
\hline Jhongshan & 0 & - & - & 4 & 367 & 92 & 8 & 2,295 & 287 & 12 & 2,662 & 222 \\
\hline Datong & 0 & - & - & 4 & 1,698 & 425 & 8 & 1,583 & 198 & 12 & 3,281 & 273 \\
\hline Wanhua & 0 & - & - & 3 & 319 & 106 & 10 & 1,304 & 130 & 13 & 1,623 & 125 \\
\hline JhongJheng & 0 & - & - & 7 & 939 & 134 & 6 & 1,264 & 211 & 13 & 2,203 & 169 \\
\hline Nangang & 1 & 660 & 660 & 1 & 65 & 65 & 7 & 5,754 & 822 & 9 & 6,479 & 720 \\
\hline Songshan & 1 & 1,650 & 1,650 & 5 & 3,934 & 787 & 3 & 1,950 & 650 & 9 & 7,534 & 837 \\
\hline Average & 2 & 6,164 & 1,591 & 6 & 1,571 & 249 & 9 & 3,853 & 425 & 17 & 7,992 & 463 \\
\hline
\end{tabular}

16 
18 Table 5. Correlation between the area and the accessibility of UG in each district in Taipei City

\begin{tabular}{|c|r|r|r|}
\hline District & First examination 1)2) & Second examination 1)3) & Third examination 2)3) \\
\hline Songshan & 0.687 & -0.037 & 0.407 \\
\hline Sinyi & 0.347 & 0.299 & 0.200 \\
\hline Da'an & -0.434 & -0.252 & 0.522 \\
\hline Jhongshan & -0.209 & -0.080 & -0.158 \\
\hline Jhongjheng & -0.174 & 0.250 & -0.184 \\
\hline Datong & 0.090 & -0.139 & 0.386 \\
\hline Wanhua & -0.133 & -0.080 & -0.022 \\
\hline Wunshan & 0.431 & 0.367 & 0.216 \\
\hline Nangang & 0.782 & 0.156 & 0.132 \\
\hline Neihu & 0.506 & -0.158 & 0.035 \\
\hline Shihlin & 0.782 & 0.295 & 0.449 \\
\hline Beitou & 0.731 & 0.392 & 0.672 \\
\hline All UGs & 0.375 & 0.088 & 0.057 \\
\hline
\end{tabular}

